\title{
The Effects of Phosphates on Mitosis
}

\author{
by Seiji TAKATORI*
}

鷹取昆二：核分裂に対する燐酸塩の影響

Received November 10, 1955

Effects of various chemical and physical agents on mitosis have been reported by many workers (cf. Politzer, 1934 et al.). Recently Huskins (1948) and others have reported that both nucleates and phosphates greatly influence on somatic mitosis and give characteristic figures different from those of other mitotic poisons. Huskins (1948) has expressed the view that reduction divisions named "somatic meiosis" are induced in Allium root tips by the effect of sodium ribose nucleate and phosphates. According to other literatures on the effects of nucleates, Wilson and Cheng (1949)have supported the view of Huskins but Kodani (1948), Shimamura and Ishikawa (1951) and Woll (1953) have denied the above mentioned occurrence. Galinsky (1949) has shown that phosphates induce numeri cal reduction of chromosomes in Allium.

The present study has been attempted for the purpose of investigating the effects of phosphate solutions on mitoses, particularly paying attention to the "somatic meiosis".

\section{Material and Method}

Bulbs of Allium cepa were placed on beakers with their bases immersed in tap water. When their roots grew to a length of $2-3 \mathrm{~cm}$ they were placed on other beakers filled with phosphate solutions in which the roots and the bases of the bulbs were immersed. After the roots were treated with these solutions at various durations of time, several roots of each bulb were cut off, and the rest left attached to the bulb were returned to tap water. Some bulbs, on the other hand, were cultured in tap water as contrcl. These excised root tips were immediately fixed with Navashin's fluid for 20-24 hours. Sections were made $16 \mu$ thick and stained with Heidenhain's iron-alum-haematoxylin.

The phosphates used were $\mathrm{NaH}_{2} \mathrm{PO}_{4}, \mathrm{Na}_{2} \mathrm{HPO}_{4}$ and $\mathrm{K}_{2} \mathrm{HPO}_{4}$, and the concentrations of each phosphate were $0.0025,0.005,0.01,0.025$ and $0.05 \mathrm{~mol}$. Duration of each treatment was 2, 4, 8, 12 and 24 hours. Experiment was carried out in an incubator at $25^{\circ} \mathrm{C}$. The $\mathrm{pH}$ of solutions, distilled water and tap water was as follows:

\footnotetext{
* Biological Laboratory, North College, Osaka University 大阪大学北校生物学研究窒
} 


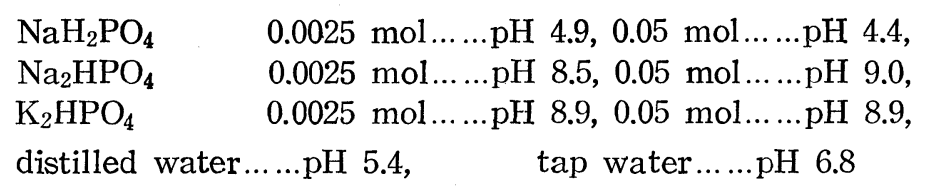

\section{Results}

\section{a. Cytological observation.}

The first externally visible effect of the phosphate treatments was suppression of growth of the roots in the case of high salt concentrations. In this case, it was observed that the higher the concentration of the solution and the longer the duration of the treatment, the greater the grade of suppression of growth. In extreme cases, some of the roots showed a little or little growth, and in some cases root tips or whole roots were softened and killed. Even in the former cases, the roots showed marked retardation of growth when they were replaced in tap water.

In respect of the structure of nuclei in early and mid prophase there seems to be little difference between the meristem of growth-suppressed roots by the treatment and the normal untreated roots. In the later stages of mitosis, however, there are conspicuous differences between them, in respect of the nuclear structure and chromosome behavior.

Important abnormalities found in the treated roots are as follows:

(i) Chromosomes in late prophase are thick (Compare Fig. 2 with Fig. 1). (ii) In metaphase some chromosomes are more or less short and thick (Compare Fig. 4 with Fig. 3). (iii) Some chromosomes, in metaphase, take an X-shape; that is, two

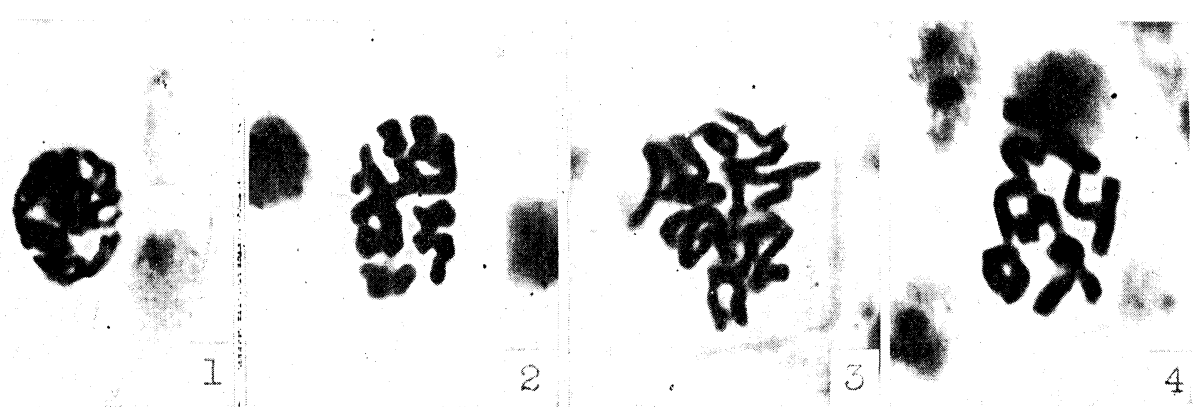

Fig. 1. Chromosomes in late prophase in an untreated root. 2. Chromosomes in late prophase in a treated root $\left(\mathrm{K}_{2} \mathrm{HPO}_{4}-0.01\right.$ mol-24 hrs. $)$. 3. Metaphase chromosomes in an untreated root. 4. Metaphase chromosomes in a treated root $\left(\mathrm{Na}_{2} \mathrm{HPO}_{4}\right.$ $-0.01 \mathrm{~mol}-12 \mathrm{hrs}$ ). All figures represent the chromosomes found in the peripheral layers of periblem. Magnification $c a 1000 \times$.

sister chromosomes are attached at the kinetochore with four arms separate (Fig. 5). This configuration has been called by Levan (1938) as "c-pair". It is very probable to assume that this configuration is caused by retardation of the kinetochore splitting, considering from the result of the investigation given in (b). (iv) 
Rarely, chromosomes in metaphase, however, separated into two groups (Fig. 6). In Fig. 6, for example, 9 chromosomes are found in the upper group; and 7, in the lower. (v) Sometimes it is observed that one or more chromosomes are apart from
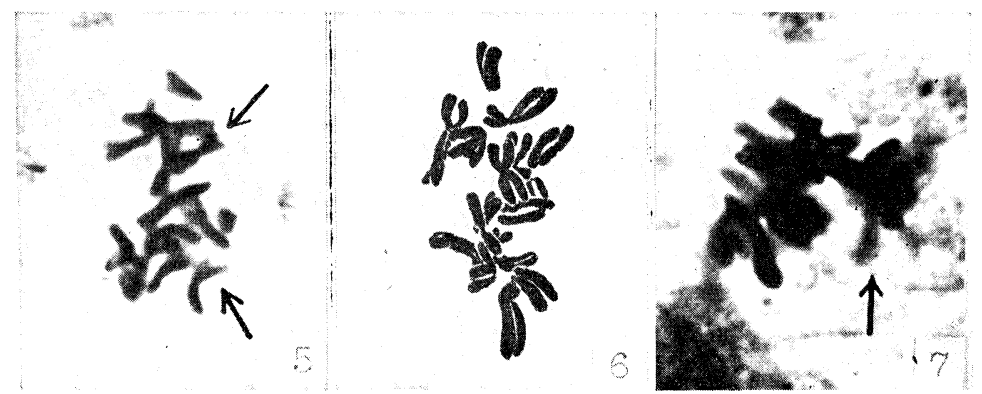

Figs. 5-7. Metaphase in treated roots.

5. X-shaped chromosomes $\left(\mathrm{NaH}_{2} \mathrm{PO}_{4}-0.025\right.$ mol-4 hrs. $)$. 6. Groupings of chromosomes into 9-7 groups $\left(\mathrm{Na}_{2} \mathrm{HPO}_{4}-0.005 \mathrm{~mol}-24 \mathrm{hrs}\right.$. $)$. 7. Some chromosomes being apart from the others which are on the equatorial plate $\left(\mathrm{Na}_{2} \mathrm{HPO}_{4}-0.005 \mathrm{~mol}-24\right.$ hrs.). Magnification $c a 1000 \times$.

the others which are on the equatorial plate in metaphase (Fig. 7). (vi) Frequently, anaphase chromosomes are scattered over the cell (Fig. 8). (vii) Frequently, one or a few daughter chromosomes are lagging on the equatorial plate while the others

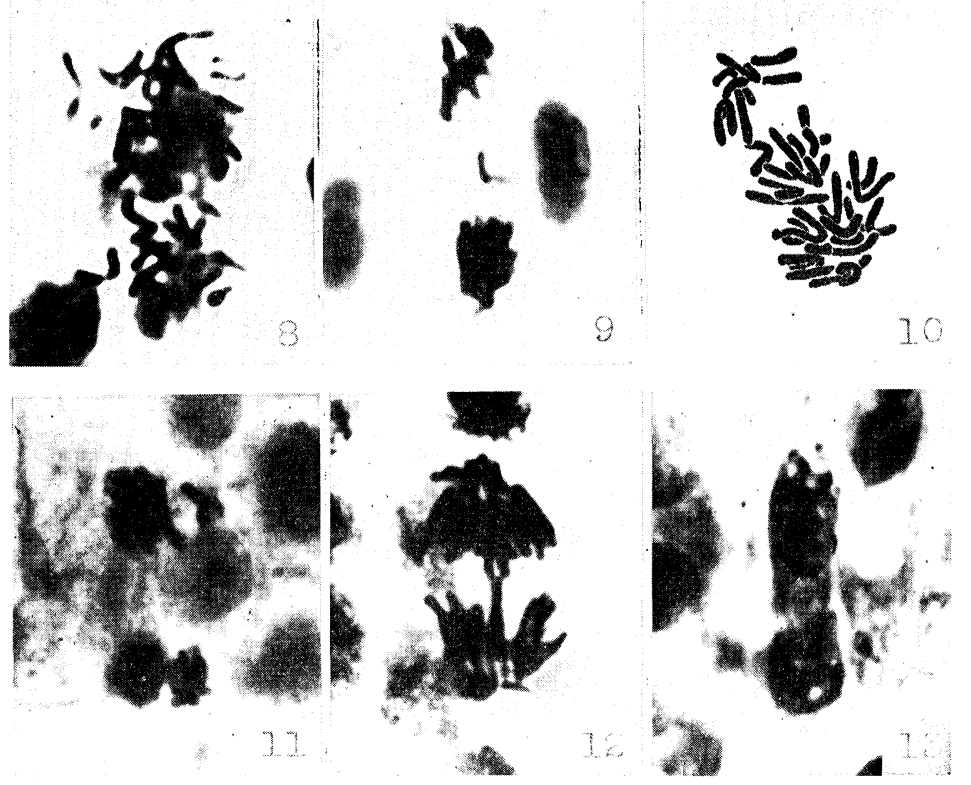

Figs. 8-13. Abnormalities in anaphase and telophase in treated roots.

8. Anaphase chromosomes scattered over the cell ( $\mathrm{Na}_{2} \mathrm{HPO}_{4}-0.01 \mathrm{~mol}-8 \mathrm{hrs}$.). 9. A few lagging chromosomes in anaphase $\left(\mathrm{NaH}_{2} \mathrm{PO}_{4}-0.025 \mathrm{~mol}-4 \mathrm{hrs}\right.$.). 10. Separation of chromosomes into approximately 7-25 groups $\left(\mathrm{Na}_{2} \mathrm{HPO}_{4}-0.025 \mathrm{~mol}-4 \mathrm{hrs}\right.$.). 11. A tetrapolar distribution $\left(\mathrm{Na}_{2} \mathrm{HPO}_{4}-0.01\right.$ mol-12 hrs.). 12. A chromosome bridge in anaphase $\left(\mathrm{Na}_{2} \mathrm{HPO}_{4}-0.005 \mathrm{~mol}-24 \mathrm{hrs}\right.$.). 13. Two bridges and unequal daughter nuclei in telophase $\left(\mathrm{K}_{2} \mathrm{HPO}_{4}-0.01\right.$ mol-8 hrs.). Magnification $c a 1000 \times$. 
have already arrived at the poles (Fig. 9). (viii) Sometimes, anaphase distribution is unequal in numbers; for example, the distribution shown in Fig. 10 is approximately 7-25. (ix) Sometimes, polypolar distribution of chromosomes in anaphase takes place (Fig. 11). (x) Pycnosis of chromosomes takes place frequently. For example, one or more chromosomes bridges are formed by sticking of free ends of the sister chromosomes (Fig. 12). These bridges are sometimes found in telophase (Fig. 13). (xi) In telophase two daughter nuclei with unequal size are frequently found (Fig. 13). These nuclei seem to be formed as a result of the unequal distribution of anaphase chromosomes.

Huskins (1948) has reported that pairing of homologous chromosomes followed by their segregation, takes place in Allium root tips treated with sodium nucleate. In spite of the careful observation, however, neither pairing nor segregation of homologous chromosomes was found in the present investigation.

b. Frequency of mitotic stages found in root tips.

To know the effects of phosphates on progress of nuclear division in root tips, frequencies of resting stage and each stage of mitosis were measured. The results obtained are shown in Table I.

Table I. Frequency of each stage of mitoses*

A: Ratio of resting and mitotic cells in $\%$.

B: Ratio of cells at each stage in $\%$.

\begin{tabular}{|c|c|c|c|c|c|c|c|c|}
\hline \multirow{3}{*}{ Treatment** } & \multicolumn{2}{|c|}{ A } & \multicolumn{6}{|c|}{$B$} \\
\hline & \multirow{2}{*}{$\begin{array}{c}\text { Resting } \\
\text { stage }\end{array}$} & \multirow{2}{*}{$\begin{array}{l}\text { Mitotic } \\
\text { stage }\end{array}$} & \multirow{2}{*}{$\begin{array}{c}\text { Early } \\
\text { prophase }\end{array}$} & \multirow{2}{*}{$\begin{array}{c}\text { Mid } \\
\text { prophase }\end{array}$} & \multirow{2}{*}{$\begin{array}{c}\text { Late } \\
\text { prophase }\end{array}$} & Metaphase & Anaphase & Telophase \\
\hline & & & & & & nor. abnor. & nor. abnor. & nor. abnor \\
\hline Control & 73.5 & 26.5 & 41.7 & 37.8 & 5.3 & $\underbrace{3.5 \quad 0}_{3.5}$ & $\underbrace{2.5 \quad 0}_{2.5}$ & $\underbrace{9.20}_{9.2}$ \\
\hline $\begin{array}{c}0.05 \mathrm{~mol} \\
\mathrm{NaH}_{2} \mathrm{PO}_{4} \\
2 \text { hrs. }\end{array}$ & 72.7 & 27.3 & 40.3 & 33.7 & 9.0 & $4 . \underbrace{1 \quad 2.8}_{6.9}$ & $2 . \underbrace{1 \quad 0.3}_{2.4}$ & $7 . \underbrace{6 \quad 0.1}_{7.7}$ \\
\hline $\begin{array}{c}0.01 \mathrm{~mol} \\
\mathrm{Na}_{2} \mathrm{HPO}_{4} \\
12 \mathrm{hrs} .\end{array}$ & 82.9 & 17.1 & 37.8 & 36.1 & 7.7 & $3 . \underbrace{3 \quad 4.9}_{8.2}$ & $1 . \underbrace{6 \quad 1.9}_{3.5}$ & $\underbrace{.7 \quad 0}_{6.7}$ \\
\hline $\begin{array}{c}0.01 \mathrm{~mol}_{2} \mathrm{HPO} \\
4 \mathrm{hrs} .\end{array}$ & 88.9 & 11.1 & 36.0 & 34.4 & 10.2 & $5 . \underbrace{8 \quad 1.2}_{7.0}$ & $3 . \underbrace{1 \quad 0.5}_{3.6}$ & $\underbrace{8.8 \quad 0}_{8.8}$ \\
\hline
\end{tabular}

* Percentages were calculated on the basis of more than 1000 mitotic cells for each treatment. ** 3 or 4 roots from one bulb were used in each treatment.

From this table the following conclusions are obtained: (1) There is little difference between the percentage of the dividing cells in the root tips treated with a $\mathrm{NaH}_{2} \mathrm{PO}_{4}(0.05 \mathrm{~mol}-2 \mathrm{hrs}$.) solution and that of the untreated root tips. In the root tips treated with $\mathrm{Na}_{2} \mathrm{HPO}_{4}(0.01 \mathrm{~mol}-12$ hrs. $)$ and $\mathrm{K}_{2} \mathrm{HPO}_{4}(0.01 \mathrm{~mol}-4 \mathrm{hrs}$.) solutions, the frequency of mitosis is somewhat lower than that of the control. 
(2) The percentages of mitotic figures in late prophase and metaphase in the treated root tips are about twice as large as those found in the untreated roots. The cause of this difference is not cleared in the present investigation, but it is highly probable that the high frequency of metaphase is caused by the delay of anaphasic polar separation, which may be due to the retardation of the kinetochore splitting.

\section{Discussion and Conclusion}

As has been described in the preceding pages of this paper, three phosphates used in this experiment disturb not only the behavior of mitotic chromosomes but the progress of mitosis.

The effects of these salts on behavior of chromosomes were essentially similar to one another. Some of the mitotic abnormalities induced by these salts seem to resemble those induced by other mitotic poisons such as nucleate, colchicine, etc. and by physical agents such as abnormal temperatures, etc.. The abnormality which was regarded as "somatic meiosis" emphasized by Huskins (1948), was not observed in the present study.

Huskins has found mitoses accompanying pairing and segregation of homologous chromosomes, followed by numerical reduction of chromosomes in Allium root tips treated with sodium nucleate solution, and has called these abnormal mitoses as "somatic meioses". Moreover, he has stated that the same phenomena are induced by phosphates also. Both Galinsky (1949) and Kato (1950) have treated the root tips with phosphate solutions and have observed the polar separation of undivided chromosomes resulting their reduction in number. It has also been reported by Kodani (1948), Wilson and Cheng (1949), Shimamura and Ishikawa (1951), Woll (1953) and others that nucleates induce the same phenomenon, but Shimamura and Ishikawa have expressed the view that this phenomenon can not be regarded as "somatic meiosis".

The distribution of 16 undivided chromosomes in metaphase into two groups found in the present study is not regarded as polar separation, but as a random grouping. This phenomenon may not be regarded as chromosome segregation. It may be concluded, therefore, that what Huskins calls "somatic meiosis" was not found so far as the present experiment was concerned.

\section{Summary}

In Allium roots treated with $\mathrm{NaH}_{2} \mathrm{PO}_{4}, \mathrm{Na}_{2} \mathrm{HPO}_{4}$ and $\mathrm{K}_{2} \mathrm{HPO}_{4}$, a number of mitotic abnormalities were observed, but neither pairing nor segregation of homologous chromosomes was observed. The fact obtained in this experiment that the mitotic figures in metaphase are more frequently observed in the treated roots than those in the control root, may be due to the retardation of the kinetochore splitting. 


\title{
Literature cited
}

1. Galinsky, I. Jour. Hered. 40: 289-295 (1949) 2. Huskins, C. L. Jour. Hered. 39: 310-335 (1948) 3. Kato, Y. Bot. Mag. 63: 25 (1950) 4. Kodani, M. Jour. Hered. 39: 327-335 (1948) 5. Levan, A. Hereditas 24: 473 (1938) 6. Politzer, G. Protoplasma-Monogaphien 7 (1934) 7. Shimamura, T. \& Ishikawa, H. Coordinating Comit. for Res. in Genetics II: 143-146 (1951) 8. Wilson, G. B. \& Cheng, K. C. Jour. Hered. 40: 1-6 (1949) 9. Woll, E. Chromosoma 5: 391427 (1953)

\section{Studies on the Lotus-Seed}

\section{On the Water Content of the Old but Still Viable Seed}

\author{
by Yoshinobu Osawa, Chiyo Saito, and Masaru ChUjo* \\ 大沢義信・斎藤千代・中条勝：蓮の種子に関する研究 \\ I. 古いが向生きている種子の含水量について
}

Received December 5, 1955

The lotus-seed retaines the vital force for some thousand years if it is buried in the peart-bed**.

It has been well known that the seed could be stored very much longer under the dried condition.

The water content of the lotus-seed is very interesting in this point of view.

This report is mainly concerned with the moisture content of the lotus-seed.

\section{Materials and Methods}

The lotus-(Nelumbo mucifera Gartnr.) seed used in this study was collected from the bottommud of Shinobazu-pond in Tokyo, Japan, during the period from April to May 1946, and it was considered that the seed ripened more than ten years before the time collected. After collecting, that was placed in the atomospheric air at the room temperature until the measurements were performed (from Sep. to Dec. 1954), but it seems that the water content of the seed might not undergo the rapid and noteworthy change, for the seed is hard and impermeablly coated.

The weight of seed was $0.6-0.9$ gram at the time determined.

The morphological characteristics did not differ from the seed harvested at present, and the ability of germination was fully maintained.

* Research Institute, Japan Anti-Tuberculosis Association

** Ohga, I. A study of the ancient but still viable fruit of the indian lotus found in the peat bed near Pulantien, South Manchuria. (1927) 